\title{
ENTRE MANEZINHOS E HAULES: \\ VELHOS E NOVOS CONFLITOS NA IDENTIDADE SOCIOESPACIAL \\ FLORIANOPOLITANA
}

\section{BETWEEN MANEZINHOS AND HAULES:}

NEW AND OLD CONFLICTS IN THE SOCIO-SPATIAL IDENTITY OF FLORIANÓPOLIS

\author{
Marina Toneli Siqueira ${ }^{\mathrm{I}}$ \\ Universidade Federal de Santa Catarina, Centro Tecnológico, Departamento de Arquitetura e Urbanismo, \\ Florianópolis, Santa Catarina, Brasil
}

R E S U M O : Pensar a cidade contemporânea significa reconhecer que a questâo cultural é um fator decisivo na produção do espaço, ainda mais em um contexto de globalização econômica e de competição interurbana que se apropria de traços culturais locais. Este artigo relaciona a produção do espaço urbano de Florianópolis com a formação de identidades socioespaciais que estabelecem relaçôes complexas entre si e com a própria cidade. Resultantes da importação de modelos urbanos externos e da imigração de contingentes populacionais diversos, esses grupos formam relaçóes que se alternam entre conflito e cooperação, tendo como resultado uma visão multifacetada e mutante acerca do desenvolvimento urbano da cidade. Dessa forma, o artigo colabora para a formação de uma visão pluralista da cidade, concluindo que a sua refundação e planejamento a partir das múltiplas narrativas de seus habitantes pode se transformar em um ato de cidadania e de modificação da sua própria cultura política.

P A L A V R A S - C H A V E : direito à cidade; identidade cultural; produção do espaço urbano; dissenso urbano; Florianópolis.

A B S T R A C T : In order to understand the contemporary city it is necessary to recognize that culture is a decisive aspect in the production of space, even more so in a context of economic globalization and urban competition that appropriates elements of local cultural. This article establishes a relationship between the production of urban space in the city of Florianópolis and the formation of socio-spatial identities, which create complex relationships both among themselves and with the city. Resulting from the importation of external urban models and the immigration of various populations, these groups that are neither fixed nor cohesive, form relationships that alternate between conflict and cooperation, resulting in a multifaceted, mutating perspective in relation to the urban development of the city. Thus, the present article collaborates with a pluralistic perspective on the city, and concludes that this form of refounding the city through the multiple narratives of its inhabitants may be transformed into an act of citizenship, since it allows for the transformations of its own political culture.

K E Y W O R D S : right to the city; cultural identity; production of urban space; urban dissent; Florianópolis.

DOI: http://dx.doi.org/10.22296/2317-1529.2016v18n1p40

$1 \mathrm{~A}$ autora gostaria de agradecer à Fundação de Amparo à Pesquisa do Estado de São Paulo (FAPESP) pelo apoio oferecido a esta pesquisa. 
Pensar o direito à cidade nas sociedades contemporâneas significa reconhecer as múltiplas e variáveis relaçôes que produzem o espaço urbano. Na presente análise, são enfatizadas as discussôes que giram em torno da globalização e dos conflitos culturais de populaçóes invadidas pela lógica de mercado ou, ainda, da migração de parcelas populacionais com traços culturais distintos, resultando na emergência de conflitos socioespaciais. Esse debate se insere no contexto mais geral da confrontação da massificaçáo do período fordista e modernista pelos movimentos sociais e culturais das décadas de 1960 e 1970, que reivindicavam mais autonomia aos sujeitos e mais liberdade de papéis dentro da sociedade, enfatizando a relevância do reconhecimento e da inclusão de identidades pessoais e locais (JAMESON; 2004; HARVEY, 2005). De fato, às históricas disputas socioeconômicas (LEFEBVRE, 1991), soma-se a questâo cultural como fator decisivo da produção do espaço urbano contemporâneo, ainda mais em um contexto de competição interurbana que se apropria de traços distintivos para a promoção e atração de usuários solventes (ARANTES, 2000; VAINER, 2000; ZUKIN, 2009). Por um lado, a questáo de como conceituar identidades culturais em um mundo cada vez mais permeável pela informaçáo e pelas trocas materiais e simbólicas torna-se fundamental para a compreensão das paisagens urbanas contemporâneas. Por outro, pode-se perguntar se é possível preservar aspectos significativos da história que forma o tecido social atual, sem submetê-los a uma lógica utilitarista (que transforma tudo em um produto passível de ser consumido) e excludente (que acaba por expulsar aquilo que gera o significado simbólico). Mais pertinente ainda é esta indagação: qual é a importância da manutenção desses atributos na atual conjuntura, em que tudo pode ser fabricado, comercializado e/ou dissimulado? A inclusão dessas questôes na agenda da justiça urbana e do direito à cidade é imprescindível para a compreensáo da produçáo do espaço contemporâneo e das diversas formas a partir das quais movimentos e organizaçóes sociais informais desafiam forças políticas, econômicas e mesmo enfoques tradicionais utilizados pela academia no (re)conhecimento das disputas urbanas.

Utilizando a literatura sobre urbanismo e produção cultural pós-modernos, o objetivo deste trabalho é, a partir de uma análise histórica, estudar o processo de formação de identidades socioespaciais conflitivas na Florianópolis contemporânea. A cidade, uma capital sempre em busca do "progresso", tem sua história marcada pelas imigraçóes de diversos segmentos populacionais e pela promoção da atividade turística, com pouco planejamento e/ou provisão de infraestrutura e serviços condizentes com a sua expansão urbana, vindo a atingir o seu rico ambiente natural. Esses processos promoveram a formaçáo de grupos sociais que se colocaram em disputa na e pela cidade, fato que tem um impacto direto na produçáo do espaço urbano local. Para analisar esses processos, este artigo faz uso de uma metodologia qualitativa e da análise de casos representativos dos conflitos atuais na produção do espaço urbano local. Longe de querer esgotar a temática, esses casos expóem grupos, lugares e momentos relevantes para a construção socioespacial da Florianópolis contemporânea. Foi realizada a revisão de bibliografia e de fontes de dados secundários, incluindo documentos gerais e legislação municipal, estadual e federal. Ademais, informantes locais e visitas a campo contribuíram para a identificação de grupos, conflitos e alianças.

O texto organiza-se em quatro partes, além desta introdução. Na primeira parte, apresenta-se a discussão teórico-conceitual sobre a questão cultural contemporânea e a formação de identidades urbanas em um contexto de expansão do urbanismo com- 
petitivo e de utilização de traços identitários tradicionais como estratégia de promoção de cidades. A partir dessa conceituação, na segunda parte, relaciona-se a produção do espaço urbano de Florianópolis com a formação no imaginário local de identidades culturais associadas a padrôes de desenvolvimento urbano local. Na terceira parte, são brevemente apresentados três casos (Ribeirão da Ilha, Jurerê Internacional e Ponta do Coral) nos quais esses grupos estabelecem relaçóes sociais complexas, alternando-se entre conflito e cooperação. Os casos expóem uma visão multifacetada e mutante acerca do desenvolvimento urbano da cidade a partir de sociabilidades emergentes. Conclui-se, portanto, que as noçốes de cultura e, por conseguinte, de identidade cultural não estão alicerçadas numa recuperação constante do passado. Ao contrário, estão sempre em diálogo com novas temporalidades e espacialidades e em relação com outros grupos e dimensóes sociais. Assim, o artigo colabora com uma visão da produção do espaço urbano a partir de um enfoque pluralista, considerando as múltiplas formas de disputa, dominação e insurgência presentes na cidade contemporânea como aspectos constitutivos da cidadania e do direito à cidade.

\section{AFINAL, QUAL É A QUESTÃo CULTURAL?}

Não é mais possível negar a importância dos aspectos culturais para a compreensão da produção do espaço urbano. O modernismo heroico e seus objetivos ambiciosos de transformação socioespacial foram transformados ao longo do século XX em um padráo universalista e homogeneizador que pouco respeitava liberdades e identidades individuais e locais (ANDERSON, 1999; HARVEY, 2005). Não à toa, a crítica ao modernismo ganhou força com a inclusão de minorias étnicas, nacionais e religiosas no debate urbano, em especial a partir dos movimentos sociais da década de 1960 nos países de economias centrais. Paralelamente, o acentuado e generalizado processo de urbanização e a migração maciça de contingentes populacionais, não somente do campo para a cidade, mas também entre cidades e países, resultaram no contato direto entre diferentes grupos e tradiçôes sociais. Essa transformação da tradicional luta de classes nas cidades em um sistema multifacetado gerou a necessidade de novas teorias, conceitos e modelos explicativos para tentar abarcar o significado desses novos padróes simbólicos. Por um lado, o multiculturalismo dos Estados Unidos da América foi ao encontro das micronarrativas das particularidades culturais, considerando as identidades culturais como estáveis e finitas e constituindo as cidades como mosaicos socioculturais fixos (MACAGNO, 2003). Por outro lado, esse modelo interpretativo não considera as novas expressôes geradas pelos contatos entre os diferentes grupos socioculturais, os quais, por sua vez, geram uma nova forma de sentido e representação cultural nos espaços de negociaçáo que reverte os limites estreitos da racionalidade, isto é, a hibridação (CANCLINI, 2006; HALL, 2006). Assim, uma identidade cultural também está em permanente mutação, não podendo ser considerada como algo uno, coeso e estável (uma essência), mas como um processo, algo que sofre transformaçôes constantes, montando estratégias e táticas cotidianas para a sua sobrevivência (CERTEAU, 1985).

As cidades tornaram-se lugares estratégicos para pensar esses conceitos, não somente porque as taxas de urbanização demonstram que o mundo é hoje majoritaria- 
mente urbano, mas também porque são nelas que, na maioria dos casos, esses contatos entre diferentes modos de vida e diferentes identidades culturais se dão. A cidade torna-se um patchwork de territorialidades realocadas e móveis. Dessa forma, se já são tradicionalmente debatidas as distintas formas de apropriação do espaço relativas a diferentes classes sociais (LEFEBVRE, 1991), nas discussōes contemporâneas sobre o urbano, é possível perceber a mesma preocupação acerca das identidades culturais, em especial com relação aos estudos sobre a dialética entre as escalas globais e locais. Portanto, ainda que sejam levados em consideração os inúmeros trabalhos sobre cidades globais (SASSEN, 1998), cidades em rede (CASTELLS, 2000), novas exigências urbanas em um contexto de globalização e competição por localizaçóes (REZENDE, 1982; LOPEZ, 1998; VAINER, 2000; SÁNCHEZ, 2003; COMPANS, 2005), entre outros, os temas das particularidades locais e da preservação de aspectos singulares de cada meio urbano vêm ganhando destaque, até mesmo pela própria preocupação de que eles desapareçam. Por um lado, ao observar a constituição urbana, é possível distinguir espaços que simbolizam modos de vida e valores particulares a cada grupo social (BOURDIEU, 1996). Sáo esses espaços, entendidos como paisagens codificadas, que podem emergir como novos espaços públicos de caráter identitário e democrático. Por outro lado, a difusão do "gosto pelo antigo", pelo exótico, ou seja, pelos mesmos aspectos distintivos, pode também ser apropriada como estratégia econômica (ZUKIN, 2009). Ao mesmo tempo que a pós-modernidade acentua o processo de globalizaçáo econômica e social, a cultura aparece como grande vedete do sistema de acumulação (ARANTES, 2000).

A internacionalização deu-se, em parte, pela incorporação de bens materiais e simbólicos de outras sociedades a partir da abertura das fronteiras geográficas de uma nação. Neste contexto, importa mais a velocidade com que se percorre o mundo do que as posiçóes geográficas fixas, já que a globalização supóe a interação funcional entre atividades econômicas dispersas, bens e serviços gerados por um sistema de muitos centros produtivos e consumidores. Assim, a cultura, incorporada pelo sistema de acumulação, torna-se uma articulação flexível, uma montagem multinacional (CANCLINI, 2006). Os objetos perdem a fidelidade com os territórios originários e tornam-se obsoletos instantaneamente, devido ao modo de produção e de consumo em contínua renovação, repleto de surpresa e divertimento. O popular acaba por tornar-se incompreensível pela multiplicidade de encenaçôes com que o folclore, as indústrias culturais e o populismo político o representam.

$\mathrm{Na}$ "lógica cultural do pós-modernismo" (JAMESON, 2004), a efemeridade dos produtos e as "modas" transformam-se em um fenômeno de massa; o consumo passa a ser não só de bens e serviços (pessoais e de negócios), mas também de lazer e entretenimento. Apoiada nos espaços revitalizados, nos eventos propagandeados e ideais para a reestruturação econômica, na fixação de novos hábitos sociais, numa arquitetura "espetacularizada", a cidade pós-moderna aparece reinserida no cenário mundial. Portanto, nos estudos atuais sobre a paisagem urbana, a tendência é enfatizar ou as novas edificaçóes e espaços pós-modernos, iguais em qualquer ponto do globo, servindo-se da mais alta tecnologia e sendo capazes de inebriar habitantes e turistas (JAMESON, 2004), ou uma paisagem pós-moderna marcada pelas "renovaçóes" de áreas consideradas degradadas que são transformadas em espaço de/para o consumo (ARANTES, 2000). Deste modo, é possível perceber duas maneiras distintas de transformação do espaço urbano: primeiramente, pelo enobrecimento de setores escolhidos, resultando 
2 Canclini (2006), por outro lado, considera que o consumo constrói parte da racionalidade integrativa e comunicativa da sociedade e sugere que é preciso pensar o que a globalização, o mercado e o consumo têm de cultural, já que, por diversas vezes, são encarados somente de forma econômica.

3 Entre os diferentes títulos, cabe destacar o de capital brasileira com melhor qualidade de vida e terceira cidade do Brasil com maior Índice de Desenvolvimento Humano Municipal (IDHM), de acordo com o último relatório da Organização das $\mathrm{Na}$ ções Unidas (ONU), publicado em 2013. Disponível em: <http://www.atlasbrasil.org. br/2013/pt/ranking>. Acesso em: 12 jan. 2015.

4 Haule é uma expressão não original de Florianópolis, mas de surfistas, sendo usada para designar quem não sabe surfar, aquele que é de fora ou ainda quem rouba a onda de outro. Neste trabalho, a expressão será adotada para nomear os novos moradores da cidade.

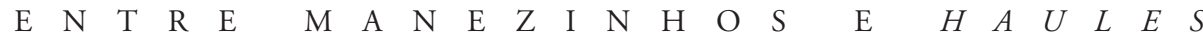

na gentrificação (SMITH, 1996), ou, em segundo lugar, pela sua transformação em um verdadeiro parque de diversóes (ZUKIN, 2003). Nos dois casos, a diversidade é apropriada por um sistema baseado na reprodutibilidade. No momento em que tudo vira cultura (ARANTES, 1996), a identidade socioespacial deriva, paradoxalmente, do consumo ${ }^{2}$. O que se consome é um estilo de vida, e, portanto, isso financia a elevação do prestígio de um determinando local ou cidade que adentra o circuito de acumulação. O pastiche, a imitação e a colagem são formas de expressão de uma cidade fabricada e simulada, sem vínculos identitários efetivos com sua formação e desenvolvimento. A própria distintividade, que era o fator atraente para o mercado, acaba-se. Desse modo, mapear uma cidade pós-moderna significa localizar cultura e poder ancorados na questão local ou no mercado global. A complexidade dessas relaçóes será apresentada a seguir, tendo como exemplo o caso de Florianópolis.

\section{A IDENTIDADE FLORIANOPOLITANA}

Florianópolis passou por um desenvolvimento bastante lento, preservando alguns de seus aspectos culturais e naturais. Foi somente a partir da década de 1950, com a busca do "progresso", muito ligada à onda desenvolvimentista e industrializante em voga no país, que elites econômicas e políticas locais procuraram mais efetivamente o seu crescimento, adequando-se a modelos externos. A consolidação de uma capital, com a instalação de diversos órgãos públicos, e a valorização da cidade por sua qualidade de vida e seu meio ambiente exuberante trouxeram grandes levas de imigrantes para a cidade. Atualmente, os títulos que Florianópolis recebeu de agências nacionais, internacionais e da mídia ${ }^{3}$, bem como a promoção de suas belezas naturais trazem mais uma expansão da cidade baseada em novos moradores. Ademais, o próprio planejamento da cidade, que considera o turismo como sua vocação, provoca o grande aumento da população durante o verão. Entre o manezinho - o sujeito tradicional da ilha, descendente de açorianos - e o haule t $^{4}$ - o vindo de fora - surgiu a tensão da responsabilidade por um crescimento acelerado, na maioria dos casos, não acompanhado de infraestruturas condizentes, solapando as comunidades tradicionais locais. É nesse sentido que é possível identificar na Florianópolis contemporânea a tensão entre esses grupos, que atuam em uma alternância entre conflito e cooperação na produção do espaço urbano. Para compreender essas relaçōes sociais complexas e instáveis, é necessário primeiro recorrer ao próprio histórico da cidade e a seus ideais de desenvolvimento urbano.

\section{OS MANEZINHOS, OU A CIDADE TRADICIONAL}

Os manezinhos corporificam o que é delineado como identidade tradicional de Florianópolis. Essa expressão, derivada de Manoel, típico nome português, designa aqueles que são descendentes dos principais colonizadores da ilha: os açorianos. É importante lembrar que, depois de sua fundação por uma bandeira vicentista e da ocupação militar para a defesa do território meridional brasileiro, a coroa portuguesa estimulou a migração de casais provenientes dos Açores para a ilha a partir de 1726 (CABRAL, 1979). Embora o núcleo principal da Vila de Desterro, nome oficial de Florianópolis no período, já estivesse consolidado em função de atividades portuárias, 
o resto do seu território continuava desabitado. Portanto, foram fundadas freguesias em balneários e comunidades rurais onde esses novos moradores iriam se estabelecer. Ademais, e em contraste com o que ocorria na época com a colonização portuguesa em outras regiôes do país, onde era promovida uma produção voltada para o comércio de exportação em grandes latifúndios, os açorianos desenvolveram um modo de produção agrícola em regime de pequena propriedade, com áreas comunais e mão de obra familiar. Baseando suas atividades na agricultura e na pesca, as freguesias funcionavam como pequenas cidades isoladas, com um pequeno núcleo principal formado pela igreja e pela praça em frente a ela, enquanto o casario foi distribuído em busca de fontes de água e terras (VEIGA, 1993). Essas localidades, praticamente autossuficientes, possuíam estradas precárias para conectar-se com o núcleo principal, dependendo, quase exclusivamente, do mar para transporte, comunicação e comércio de produtos.

Esse modelo de ocupaçáo significou, por um lado, o isolamento socioespacial que garantiu a manutenção das tradiçôes açorianas em Florianópolis. Por outro, o isolamento e a emergência de novos modos de vida locais geraram tradiçóes originais da Ilha de Santa Catarina. Um desses novos traços identitários é a lenda sobre as mulheres consideradas bruxas. Embora em nenhum momento tenha havido fogueiras santas em Florianópolis, tal como as que ocorreram na Europa, essas mulheres - curandeiras, parteiras ou mesmo mulheres consideradas más ou feias - eram temidas e odiadas pela população tradicional da cidade e adentraram o imaginário popular para explicar o que era considerado inexplicável. Franklin Cascaes, um dos autores locais mais conhecidos, publicou os relatos dessas histórias, contadas pelos próprios manezinhos e escritas, inclusive, por um deles (CASCAES, 2000). Até os dias atuais, as histórias continuam sendo contadas e acreditadas, fazendo parte do imaginário simbólico de Florianópolis, que é chamada, inclusive, de Ilha da Magia.

Um outro aspecto singular da populaçáo descendente de açorianos presente ainda contemporaneamente é a linguagem. O manezinho utiliza expressôes portuguesas antigas, muitas vezes sendo considerado como um português arcaico e náo comum ao resto do país. A fala é cantada e "chiada". Esse chiado, bastante forte, assemelha-se à troca do "s" pelo "ch", dizendo "tresch", em vez de três. Com a fala com o outro sempre na segunda pessoa do singular (tu), o manezinho ainda conjuga o tempo passado de forma peculiar: em vez de "tu fizeste", ou "tu viste", ele diz "tu fizesse" e "tu visse". Ademais, o manezinho fala extremamente rápido. Todos esses fatores contribuem muito para dificultar a compreensão de seu linguajar, que se transformou em uma espécie de código de identificação. Aliás, a fala do florianopolitano constitui-se em parte fundamental da identidade da populaçáo da Ilha de Santa Catarina, como será exemplificado ao longo deste texto. Esse é um motivo de orgulho ou um traço a ser disfarçado com vergonha, dependendo da aceitação do seu portador ou do meio no qual ele se encontra.

A pesca, a horta e a plantação, os animais, a cachaça, a farinha de mandioca, a renda de bilro e a cerâmica são as atividades econômicas normalmente associadas ao que é tradicional de Florianópolis. A Farra do Boi durante a quaresma católica, a festa de Santo Antônio e a procissão de Nossa Senhora dos Navegantes (protetora dos pescadores), o Boi de Mamão em julho, o pau-de-fita, o Terno de Reis, a Festa do Divino, a reunião para tomar o caldo de peixe depois do fim da pesca (uma espécie de "festa da cumeeira" entre todos que participaram da partilha da vez) são as festas religiosas e pagás dos Açores e agora típicas de Florianópolis (VEIGA, 1993). Levar o passarinho 
para passear em gaiolas, disputar um campeonato de canto de curiós no "curiódromo”, jogar dominó na Praça XV, discutir política no Senadinho (café em uma esquina popular no centro da cidade) e comer caldo de berbigão no Mercado Municipal são estratégias de adaptação dessa população à vida urbana e de manutenção de seus hábitos para a sua sobrevivência em novos tempos. Os açorianos desenvolveram um modo de vida característico que continua vivo e circulando pelas ruas da cidade contemporânea. Entretanto, o crescimento urbano acelerado da cidade nas últimas décadas tem ameaçado a manutenção dessas características, sobretudo se se leva em conta que, historicamente, foram buscados modelos de desenvolvimento externos à cidade e considerados mais "avançados" que o modo de vida tradicional do manezinho.

\section{OS HAULES COMO RESULTADO Do MODELO DE DESENVOLVIMENTO URBANO DE FLORIANÓPOLIS}

Não é raro encontrar muros pichados em Florianópolis com os dizeres "fora haules" ou comentários, em reportagens e mídias sociais, sobre o fato de os problemas da ilha serem resultado da vinda de levas de turistas e imigrantes de outras cidades catarinenses, de outros estados brasileiros ou mesmo de outros países, o que gerou inclusive a imagem popular e estereotipada de que os moradores locais são xenófobos. Como existem dinâmicas mais complexas do que o simples aumento populacional para gerar os problemas de crescimento desordenado, degradação ambiental e mobilidade urbana, entre outros, pode-se afirmar que os conflitos socioespaciais emergiram também da busca incessante pelo "progresso", após os diversos "diagnósticos" que caracterizaram Florianópolis como uma cidade atrasada frente ao padrão de desenvolvimento moderno e industrial brasileiro. A pressão pelo desenvolvimento, portanto, advinha das próprias elites políticas e econômicas da cidade, que, historicamente, estabeleceram uma hierarquia social que fez com que

[...] os componentes rurais da estrutura social de Desterro fossem neutralizados pelos componentes urbanos e que o sistema de atribuição de status, o estilo de vida e as formas dominantes de pensar se orientassem muito mais pelos valores dos grupos urbanos (militares, administradores e comerciantes) que dos grupos rurais (CARDOSO; IANNI, 1960 , p. 20, grifos nossos).

Dessa forma, os investimentos públicos e privados ao longo do século XX buscaram a adequação da cidade a padróes externos e ameaçaram diretamente o núcleo de sociabilidade tradicional estabelecido por manezinhos e nas Freguesias. A forma mais direta para identificar esse padrão é observando o planejamento urbano formal da cidade.

Em 1954, foi aprovado o primeiro Plano Diretor da cidade e instituído um novo código municipal. O plano era constituído de uma revisão histórica, do "diagnóstico" dos problemas da capital e de um projeto de planificaçáo. Elaborado a partir de uma encomenda a um grupo de trabalho não original da cidade, o documento preconizava, como objetivo básico, retirar a cidade do atraso e alcançar o desenvolvimento e o progresso que a levariam à modernidade (RIZZO, 1993). Seguindo os modelos da época, em especial o urbanismo progressista idealizado e difundido nos Congressos Internacionais de Arquitetura Moderna (CIAMs), o plano adotou parâmetros racionalistas 
e chegou inclusive a prever um centro de governo de estilo modernista (PAIVA; RIBEIRO; GRAEFF, 1952). Para retirar a cidade do "atraso", o plano definiu, também, três propostas principais: um porto moderno (que nunca foi instalado), um centro universitário e a expansão da atividade turística, considerada ainda como função secundária. O principal eixo de desenvolvimento idealizado conectava o continente e a ilha pela parte sul da península central, com a construção de uma via expressa nesse sentido (Avenida Tronco), embora já se propusesse também a atual Avenida Beira-Mar Norte, conectando o centro da cidade às regiôes ao norte, leste e nordeste da ilha, que no período ainda eram ocupadas por freguesias bastante isoladas. É importante notar que o plano teve um impacto bastante limitado na cidade, com o primeiro zoneamento urbano proposto para Florianópolis sendo modificado ao longo do tempo. Das proposiçóes implantadas, restam majoritariamente aquelas de caráter rodoviário que continuaram presentes nos planos seguintes (PEREIRA, 2000).

Também inserido dentro da dinâmica nacional na qual o planejamento urbano cedeu lugar ao planejamento territorial, perdendo a sua especificidade como esfera de reflexão e intervenção (RIZZO, 1993), na segunda metade da década de 1960, começa a ser desenvolvido o Plano de Desenvolvimento Integrado da Área Metropolitana de Florianópolis (Lei 1440/76). Esse é o mesmo período no qual o planejamento metropolitano ganhou força no país, em especial após a criação do Serviço Federal de Habitação e Urbanismo (SERFHAU). Depois de um levantamento realizado em todo o país, essa instituição identificou as diversas regióes metropolitanas brasileiras, incluindo as outras duas capitais estaduais da regiâo Sul, mas não Florianópolis. $\mathrm{Ou}$ seja, era necessário, mais uma vez, retirar a cidade do atraso. Nesse caso, o plano apoiava-se na ideia de que a regiáo de Florianópolis e o próprio estado de Santa Catarina só poderiam se desenvolver se houvesse a sua integração e homogeneização, partindo da própria capital como polarizadora para o resto do estado. Portanto, seria necessário priorizar os investimentos em Florianópolis para transformá-la num grande centro urbano. Por um lado, continuava-se reforçando o caráter administrativo da capital, com a proposição de um centro administrativo, institucional e financeiro da área metropolitana a se consolidar, incluindo: a nova ponte ilha-continente, um grande aterro para dar suporte às diversas conexôes viárias, os terminais rodoviários estadual e municipal, o Centro Cívico, o Túnel do Morro do Penhasco e os prédios do executivo, legislativo e judiciário. Por outro lado, estimulava-se a atividade turística com a criação de um Setor Oceânico Turístico na orla leste, abarcando o território de freguesias tradicionais, como a Lagoa da Conceição. Várias modificações foram feitas nessa proposta original até a aprovação do plano em 1976, que manteve, majoritariamente, as intervençôes viárias como foco principal (SUGAI, 1994), conectando não somente os espaços intraurbanos (núcleo central e freguesias), mas também o espaço metropolitano e o resto do país, após a construção de rodovias estaduais e federais, em especial a ligação com a BR-101.

Nessa mesma direção, o programa do governador Colombo Salles (1971-1975), chamado de Açáo Catarinense de Desenvolvimento e apoiado no programa de metas do presidente Médici, priorizou o setor de transportes e a expansão industrial no estado. Foram construídas a rodovia SC-401 (ligando o núcleo central aos balneários norte), a rodovia SC-404 (conectando a parte leste da cidade) e a Ponte Colombo Salles, juntamente dos acessos e do aterro continental, já prevendo o acesso à terceira ponte, Pedro Ivo Campos (concluída em 1991) e uma futura Avenida Beira-Mar, co- 
nectando os bairros de Coqueiros e Estreito, concluída somente em 2012. Entretanto, a obra viária mais significativa do período, e talvez até hoje, foi a Via de Contorno Norte, Avenida Beira-Mar Norte, iniciada na década de 1960. Essa foi a primeira via expressa intraurbana da cidade e teve grande importância na sua divisão territorial. A abertura dessa avenida, além de garantir a acessibilidade e a consequente valorização da área (SUGAI, 1994), procurou dar uma marca de modernidade a esse setor. Durante o mesmo período (década de 1970), foram também se multiplicando os empreendimentos imobiliários, em especial loteamentos e condomínios para grupos de alta renda nas regiōes norte e nordeste da ilha para a formação dos balneários turísticos, ao mesmo tempo que o próprio Estado investia nessas áreas, favorecendo diretamente esse segmento populacional. Os empreendimentos, principalmente nas praias no norte da ilha, receberam grande impulso pela vinda de turistas brasileiros e estrangeiros, sobretudo argentinos, uruguaios e paraguaios, durante a década de 1980. Vale ressaltar a dimensão desses empreendimentos, muitos dos quais apresentavam grandes extensóes e tornaram-se bairros da cidade contemporânea, como é o caso de Jurerê Internacional, que será mencionado novamente neste texto.

Além do turismo, a implantação de órgãos públicos que reforçavam o caráter administrativo da capital catarinense gerou um grande impacto econômico, urbanístico e populacional. Merece destaque, entre eles, a Universidade Federal de Santa Catarina (UFSC), que possuía recursos superiores aos do próprio município no período e estimulou a vinda de profissionais de outras regiôes do país, bem como o desenvolvimento do setor terciário local. A localizaçâo do campus, conjuntamente com outros órgãos públicos, em uma área ainda bastante desabitada e de ocupação rural impulsionou o crescimento da cidade. Essa localização no bairro da Trindade serviu também como um meio de polarizaçáo do crescimento no nordeste da ilha, apresentando alto incremento na construçáo civil e intensificaçáo do parcelamento do solo (SUGAI, 1994).

Esse modelo de crescimento - focado nas áreas turísticas e nos arredores dos órgãos públicos - explica o fato de que durante a década de 1980 tenham sido aprovados planos urbanísticos somente para essas áreas, a Lei da Trindade (Lei 1.851/82) e o Plano Diretor dos Balneários, em 1985 (Lei 2.193/85). Incluídas neste último caso, as Áreas de Incentivo à Hotelaria ilustram os benefícios concedidos ao turismo de alta renda, quando se observa que a lei determinava que caso os hotéis fossem classificados de três a cinco estrelas estaria liberado o número máximo de 12 pavimentos, devendo os demais ficarem restritos a dois pavimentos. Esse quesito causou bastante polêmica, sendo alterado o número máximo de gabaritos para quatro, através da Lei 3.014/88 (REIS, 2002).

Finalmente, em 1997 foi aprovado um novo Plano Diretor (Plano Diretor do Distrito Sede de Florianópolis Lei 01/97), 21 anos depois de sua versão anterior. Uma quantidade expressiva de leis foi aprovada durante esse período, e, como essa legislação passou a vigorar somente em 1998, a Câmara Municipal já tinha realizado diversas alteraçóes, principalmente no zoneamento, o que veio a permitir, por exemplo, a implantação de um shopping center em área de uso residencial e a alteração do número máximo de gabaritos, entre outros. Esse plano propôs um planejamento de forma fragmentada desde a separação do distrito sede do município com os demais, reforçando, portanto, o contraste entre núcleo central, freguesias e balneários; não propôs, por sua vez, medidas sobre a regiáo metropolitana, há muito concebida, pouco investida 
e sofrendo com o movimento pendular das populaçóes que trabalham na capital, mas moram nos municípios vizinhos. Foi, enfim, um plano de ocupação do solo urbano e não um Plano Diretor que se aprofundou em diretrizes de desenvolvimento como um todo, chegando ao ponto de não tratar e prever os equipamentos e infraestrutura de serviços básicos, como os sistemas de abastecimento de energia, água e sistemas de saneamento pluvial e de esgotos. Dele, a proposta que mais chama atenção é a verticalização da cidade, que está conduzindo ao adensamento, e um sistema de parcelamento do solo colonial, atendendo aos interesses da indústria da construção civil, mas não ao bem-estar e à mobilidade urbana. Claramente, a ampliação do espaço construído, com a respectiva queda na qualidade estética da paisagem urbana e da qualidade de vida, está sendo a consequência da execução de tal política. Finalmente, o plano, por mais necessário que fosse para um ambiente natural de imensa fragilidade, não continha um Relatório de Impacto sobre o Meio Ambiente, nem referências à sustentabilidade ambiental.

Com um plano novo sendo aprovado somente em 2014, ou seja, quase 20 anos após o plano anterior e ainda não implantado efetivamente ${ }^{5}$, não é de se estranhar os inúmeros impactos negativos do crescimento urbano acelerado da cidade. Ademais, esses impactos negativos também são encarados pela população como resultantes de um processo excludente que não levou em consideração as comunidades locais, já que existem inúmeras polêmicas nos mecanismos de participação popular na gestão e no controle desse novo plano diretor. Um último fator ainda marca a produção do espaço na Ilha de Santa Catarina nas últimas décadas: o fim do seu diagnóstico de atraso para se tornar o "sonho de consumo" de brasileiros e estrangeiros e, mais uma vez, estimular a imigração de novos contingentes populacionais.

O que muda em Florianópolis advém de fatores externos e internos. Os fatores externos ligam-se à divulgação de novos ideários de cidade através dos rankings nacionais e internacionais, inclusive nas "cartilhas de boas maneiras" de agências multilaterais como a ONU e o Banco Interamericano de Desenvolvimento (BID); à valorização de um modelo de qualidade de vida com uma relação mais estreita com a natureza; ao incremento da atividade turística no mundo e no país; e à difusão de novos modos de habitação com o processo de suburbanização das elites em condomínios residenciais, muitas vezes fora da cidade onde realiza a maior parte das suas atividades. Com relação aos fatores internos, o que muda na cidade é o impacto do histórico, constante e maciço investimento para a atração de "usuários solventes" (VAINER, 2000), tanto moradores quanto turistas ${ }^{6}$. Com a exuberância do ambiente natural de Florianópolis, a atividade turística, considerada sua vocação, também é explorada sem limites precisos (LIMA, 2002; REIS, 2002), enquanto o setor terciário cresce baseado nos órgãos públicos da capital catarinense. A cidade passa, enfim, por uma grande valorizaçáo material e simbólica, o que acarreta grandes transformações socioespaciais. Não é de se estranhar, portanto, que os novos grupos sociais resultantes dessas transformaçôes entrem em relação direta com a cultura tradicional da ilha, causando momentos de conflito, mas também de cooperação.
50 Plano Diretor de 2014 foi aprovado após inúmeras polêmicas, incluindo a aprovação de mais de 300 emendas na Câmara de Vereadores e a dissolução de seu Núcleo Gestor. Em julho de 2015, o Tribunal Regional Federal da 4a Região julgou a ação civil pública movida pelo Ministério Público Federal e decidiu pela realização de novas audiências públicas e novo encaminhamento do documento para aprovação na Câmara de Vereadores. Em agosto de 2016, o processo ainda não havia sido concluído e o plano ainda não havia sido efetivamente implantado.

6 É importante mencionar que a atração também foi da população de baixa renda, migrante à procura de emprego. Uma vez que o valor da terra na cidade é muito alto, essa população instala-se ou nas cidades vizinhas ou em ocupações na ilha, na maior parte das vezes nas Áreas de Preservação Permanente (APP), causando danos ambientais e, muitas vezes, riscos para os próprios moradores (PIMENTA, 2005). 


\section{ENTRE MANEZINHOS E HAULES: AS SOCIABILIDADES EMERGENTES E INSURGENTES}

Com uma cultura de planejamento urbano que valorizou modelos externos, a "modernização", o "progresso" e o "desenvolvimento" de Florianópolis podem ser vistos a olho nu: a derrubada do casario histórico, a verticalização do núcleo central e a ocupação acelerada das antigas freguesias para a formação dos balneários, e um novo sistema viário, tornando o interior da ilha e outras cidades do país mais próximas. Como a mudança foi grande no aspecto físico da cidade, ela reflete e refletirá tanto no modo de vida dos moradores mais antigos quanto na configuraçáo populacional da cidade atual. $\mathrm{O}$ antigo e o novo estáo em contato direto e cotidiano, e, nesse contato, novas sociabilidades emergem e modificam a realidade socioespacial local. Um caso claro dessa transformação é a Freguesia do Ribeirão da Ilha. Formada no século XVIII com a vinda dos imigrantes açorianos, sua ocupação pelo homem europeu é considerada a primeira da ilha (PEREIRA; PEREIRA; SILVA NETO, 1991). Próxima do continente e da vila sede, a Freguesia do Ribeirão possuía grande relevância econômica e social na rede de núcleos formada desde o Brasil colônia. Foi no período de modernização acelerada identificado em Florianópolis que ocorreram transformaçóes no Ribeirão da Ilha que o alteraram definitivamente. Enquanto se impulsionava o desenvolvimento da cidade no sentido nordeste, a importância do Ribeiráo da Ilha declinou. Os novos modos de produçáo contrastaram e competiram com o modelo de produção local, baseada na pequena lavoura, pesca artesanal e moinhos para produção de farinha e cachaça. Conjuntamente, a desativaçâo do porto de Desterro e a construção e o melhoramento de estradas de conexão na ilha acarretaram a decadência da economia tradicional. A emergência de novos modos de vida, tanto de sociabilidade quanto de hábitos privados, promoveu a desvalorização da cultura local. As edificaçôes sofreram bruscas alteraçóes, a população abandonou as atividades tradicionais, e a mídia decretou "a morte" do Ribeirão da Ilha, situação que foi alterada, ao menos parcialmente, somente a partir da década de 1980.

As mudanças pelas quais Florianópolis passa a partir da valorização socioespacial e do aumento da atividade turística também impactaram o Ribeirão da Ilha (SIQUEIRA, 2008). Por um lado, a valorização do Ribeirão da Ilha promoveu políticas de preservaçáo do patrimônio histórico local, havendo o tombamento de edificaçôes, restaurações e incentivos. Embora mais efetivos, esses programas não são menos contraditórios. Enquanto não existe uma forma mais efetiva de diálogo, a população local demonstra não compreender o significado da prática patrimonial e acaba por descaracterizar as edificaçôes para adaptá-las às demandas cotidianas, como a instalação de janelas de materiais e estilos modernos em contraste com as tradicionais venezianas de madeira e sem vidro. Por outro lado, enquanto as instituiçôes públicas agem rigidamente contra qualquer forma de infração, multando os moradores locais, elas próprias atuam descaracterizando o patrimônio histórico, como pode ser visto na instalação de lamparinas fixadas às edificaçóes (SIQUEIRA, 2008). Nesse caso, com o intuito de especificar uma área histórica, o governo municipal introduziu elementos estranhos ao contexto local, já que a energia elétrica somente foi instalada no Ribeirão durante a década de 1950 e nunca com o modelo acoplado às residências. Além da desca- 
racterização das fachadas, através da perfuração das paredes de edificaçóes de grande relevância histórica no conjunto arquitetônico ilhéu, a ação pública acabou por forjar uma situação inexistente.

A expansão do turismo, não obstante, afeta o Ribeirão da Ilha pela formação de uma nova área de interesse, ao conjugar o patrimônio histórico e os traços culturais tradicionais ao polo gastronômico constituído por meio da maricultura. Historicamente, as formas tradicionais de pesca perderam a sua importância na economia florianopolitana devido à competitividade com a pesca industrial e à baixa taxa de lucros em a relação a esta última. Como forma alternativa de geração de renda para a população, a UFSC desenvolveu, com os moradores, um programa de cultivo de ostras, importando as suas sementes do Oceano Pacífico (MACHADO, 2002). Embora com grande reconhecimento e produção, a maricultura não chega a afetar substancialmente a renda da população local, que na maioria dos casos não é a proprietária das fazendas, e ainda promove a privatizaçáo do mar, espaço de sociabilidade habitual do Ribeirão. A divulgação da área como polo turístico e gastronômico ainda acarretou a venda das edificaçóes e de lotes para novos moradores, enquanto o ribeironense transferiu-se para as encostas dos morros ou para outros bairros, provocando a gentrificação, mesmo que parcial, da área (SIQUEIRA, 2008; SMITH, 2002).

Nesse contexto, o turismo e a imigração de novos moradores são encarados por muitos manezinhos como uma invasáo da cidade, e a "nova cara" de Florianópolis, como um abuso, a exploração de uma terra que lhes pertence. Um marco da disputa entre manezinhos e haules foi a eleição para a prefeitura municipal de 1996, logo em um período de aprovação de um novo Plano Diretor para a cidade. Naquele momento, partidos ligados às famílias tradicionais locais fomentaram uma campanha contra a gestão baseada na força dessa invasão e contra "os estrangeiros que querem mandar na ilha", já que o prefeito naquele momento era natural de Porto Alegre ${ }^{7}$. Ademais, esse embate já saiu dos canais formais de participação para tomar forma de manifestaçóes populares e conflitos cotidianos. Além das pichaçóes e manifestaçóes individuais na mídia, coletivos começaram a se organizar. Por meio de um movimento de valorização da figura do manezinho, essa alcunha, antes pejorativa, por ser associada a piadas sobre portugueses (FANTIN, 2000), tornou-se um elogio, um orgulho para os moradores mais antigos da ilha ${ }^{8}$. Um exemplo é a Medalha Manezinho da Ilha Aldírio Simóes para premiar os "manezinhos do ano", sendo inspirada em um jornalista conhecido localmente. Assim, promovendo um dos traços da identidade local, a já mencionada linguagem peculiar, um dos ganhadores, ao ser premiado, subiu ao palco e, voltandose ao público, falou algo indecifrável nesse linguajar característico. Ao terminar, disse que quem soubesse o que ele havia falado era um verdadeiro manezinho. Ou seja, um morador novo, um haule, não entenderia o que ele disse?

Manezinhos e haules, entretanto, não são grupos estáticos e agem tanto em conflito como em cooperação no desenvolvimento urbano da ilha. Com os problemas criados pela expansão urbana desordenada, pela mobilidade deficiente e pela degradação ambiental, entre outros, novos grupos formaram-se, entrecortando manezinhos e haules. Um exemplo claro são os novos empreendimentos turísticos na ilha. Por um lado, enquanto manezinhos culpam os haules pelos problemas urbanísticos contemporâneos, os novos moradores também procuram defender a qualidade de vida que primeiro os atraiu na cidade. Essa complexificação é clara quando se trata dos movimentos de defesa do meio ambiente contra, por exemplo, um complexo turístico
70 prefeito, na ocasião, era Sérgio Grando, ligado à Frente Popular, uma coligação de partidos considerados de esquerda. Entretanto, a presença de "estrangeiros" nas administrações públicas de Florianópolis e do estado de Santa Catarina é fato comum e atual.

8 Muito dessa inversão, conforme descrita por Márcia Fantin (2000), foi encarnada na figura do manezinho mais conhecido no resto do Brasil, Gustavo Kuerten, que se tornou campeão mundial de tênis em Roland Garros em 1997, 2000 e 2001, entre outros torneios, e ajudou a divulgar a cidade e a cultura local.

90 próprio material de divulgação da medalha pela Câmara Municipal de Florianópolis enfatiza o linguajar peculiar da população tradicional. (Disponível em <http://www.cmf.sc. gov.br/noticias/3306b4b1 - $594 \mathrm{~b}-4 \mathrm{c} 6 \mathrm{~d}-9 \mathrm{ffc}$ d9500e78679d>. Acesso em: 22 jan. 2016). 
10 As disputas pela Ponta do Coral foram registradas pelo blog do movimento em defesa da Ponta do Coral (Disponível em: <https:// parqueculturaldas 3 pontas. wordpress.com/>. Acesso em: 22 ago. 2015) e pela mídia local (Disponível em: $<$ http://diariocatarinense. clicrbs.com.br/sc/geral/pagina/ponta-do-coral.html>. Acesso em: 22 ago. 2015). a ser construído no último ponto de geografia natural em meio ao aterro da Avenida Beira-mar Norte, afetando a fauna e a flora local. Fora um processo de venda bastante duvidoso na década de 1980 e diversos projetos conflitantes para a área (SILVEIRA, 2005), a localização da Ponta do Coral ainda conta com um dos últimos vestígios das comunidades tradicionais naquela área da cidade, com ranchos de pescadores e um parecer favorável à preservação da área pelo Serviço de Patrimônio Histórico, Artístico e Natural do Município (SEPHAN). Finalmente, em um cenário de falta de espaços públicos que não sejam as praias e as áreas de preservação permanente, um movimento protagonizado, em especial, por professores das universidades locais pediu a inserção da área em um complexo de parques municipais.

Em 2014 e 2015, com o polêmico licenciamento ambiental da obra, as disputas ficaram mais claras, com as elites econômicas e políticas locais unindo-se a manezinhos favoráveis ao desenvolvimento de um complexo turístico na Ponta do Coral com grande área aterrada, marina e hotel. Apesar das contradiçôes com relação ao zoneamento local, modificado e mais restritivo com o novo Plano Diretor aprovado no início de 2014, foi somente com a intervenção dos Ministérios Públicos Estadual e Federal que as obras foram barradas, com o argumento da falta de medidas para prevenir e resolver os problemas do polo gerador de tráfego em uma área da cidade que já sofria com problemas de mobilidade urbana.

Como a área continua sendo uma propriedade privada, o conflito se mantém, com o movimento social pedindo a criaçáo do parque e com acusaçóes de que os políticos locais estão agindo em conjunto com os empreendedores. Por outro lado, manezinhos, em falas cotidianas e na mídia local, chamam o movimento de baderneiros, contra o "progresso" da cidade ou, ainda, que o local servirá somente para o consumo de drogas e para abrigar "vagabundos". Sem uma decisão do governo municipal, em 2015, as tensôes continuaram, ocorrendo ocupaçóes pelo movimento social, seguidas de operaçóes da polícia e manifestaçóes formais e informais contra o empreendimento ${ }^{10}$.

Essa complexificação social, que transborda estereótipos e movimentos organizados, também inverte papéis de acordo com a ocasiāo. Dessa forma, a grande exposição da cidade na mídia e o aumento dos interesses econômicos na cidade, ligados principalmente à atividade turística, traz uma nova tensão: novos grupos de haules investem em empreendimentos na cidade unindo-se, em parte, aos interesses das elites locais, mas contra os "haules baderneiros" mais antigos. Por outro lado, esses novos moradores e investidores também podem ser adversários da população tradicional de Florianópolis, tanto da elite quanto daqueles de renda mais baixa, por "roubarem" o que deveria ser deles. Essa é uma relação bastante ambígua: de união, quando é do interesse de ambos, e, ao mesmo tempo, de disputa, quando o tema é o maior usufruto da cidade. Numa relação mais utilitarista, esses "usuários" da cidade investem ou moram em bairros e edifícios luxuosos, inaugurando, assim, um novo movimento pendular. Enquanto a família mora permanentemente na cidade, os adultos (um ou o casal) trabalham em outras cidades, incluindo capitais de outros estados, como São Paulo, voltando diariamente ou nos finais de semana para Florianópolis.

Esse foi o achado em Jurerê Internacional, um investimento de um grupo gaúcho (Habitasul) iniciado na década de 1970, ao lado de um núcleo pesqueiro (SIQUEIRA, 2008). É interessante notar que o empreendimento somente obteve o sucesso imobiliário e turístico que o transformou em uma das áreas mais visitadas na cidade na última década, após a mudança no projeto urbanístico com a contratação de uma 
empresa originária dos Estados Unidos - mais uma vez, isso comprova a importação de modelos externos à cidade. Assim, por um lado, iniciando um novo padrão de ocupação e estilo de moradia, Jurerê Internacional é conhecido como um dos balneários mais exclusivos do país, com mansóes destinadas somente para segunda residência e veraneio; por outro, cada vez mais sáo construídas residências permanentes de haules que se mudam definitivamente para Florianópolis.

É claro que as formas de conflito e cooperação entre manezinhos e haules são visíveis de diversas maneiras: em espaços/bairros distintos; partidos políticos opositores; nas mídias mais populares da cidade; na Internet, em páginas, blogs e comunidades virtuais intituladas "Fora haules" ou "Eu odeio manezinhos"; e nas atividades mais diárias como em conversas e discussóes acaloradas, brigas nos supermercados, rachas no trânsito e pichaçôes nos muros. Entretanto, como é possível perceber em casos como os do Ribeirão da Ilha, da Ponta do Coral e de Jurerê Internacional, essas identidades de manezinhos e haules não são fixas ou coesas. Pelo contrário, as mudanças sofridas pelos dois grupos no processo de encontro podem trazer mais riqueza e complexidade ao debate sobre o futuro de uma cidade mais democrática e inclusiva.

\section{CONSIDERAÇÕES FINAIS: NECESSIDADES E CONFLITOS DA CIDADE CONTEMPORÂNEA}

As noçôes de cidade e cidadania são interdependentes. Em lugar de tratar diretamente da genealogia dessa conexão, este artigo discutiu como a questão das identidades culturais, formadora de direitos dos cidadãos, emergiu na discussão atual sobre a produção do espaço urbano e o direito à cidade. As cidades passam por um momento de redefiniçáo de papéis em que as fronteiras materiais e simbólicas tornam-se cada vez mais porosas, já que estão em constante comunicação. Em um mundo finalmente globalizado, mas por meio do poder de poucos, da exclusão e fragmentaçáo social, da crescente despolitização que destrói os espaços públicos e gera espaços homogêneos e dissociados de seu contexto histórico e social, da indústria cultural que se apropria dos menores, porém mais rentáveis, traços distintivos, é possível indagar em que medida expressóes locais ou populares conseguem (ou conseguirão) formar um espaço efetivamente público e democrático, indo além da dominação externa e interna da sociedade na qual elas emergem.

Este trabalho partiu da noção de que as identidades culturais e, consequentemente, a cidadania não são completas, acabadas, coesas e fixas. Pelo contrário, elas são construçôes sociais, sempre em processo, resultantes de práticas localizadas espacial e temporalmente. Assim, a polarização entre cultura popular e cultura dominante, que defende a pureza da primeira, como se ambas fossem independentes, não é cabível. Nunca estando somente em condiçáo de receptora passiva, a cultura popular ou tradicional negocia com modelos alternativos, transformando, resistindo ou mesmo negando atributos exteriores. O seu importante papel na produção do tecido social aparece justamente no espaço cotidiano, heterogêneo em práticas e temporalidades.

Em uma cidade como Florianópolis, esses traços tornam-se ainda mais complexos. Através de um processo de desenvolvimento urbano pautado na "busca pelo progresso", essa cidade vem sendo marcada, há décadas, por ciclos migratórios de populaçóes que convivem com as comunidades mais antigas da ilha. Estas últimas, ou 
Marina Toneli Siqueira é arquiteta e urbanista pela Universidade Federal de Santa Catarina (UFSC); mestre em Arquitetura e Urbanismo pela Faculdade de Arquitetura e Urbanismo da Universidade de São Paulo (FAU/ USP); doutora em Urban Planning and Policy pela University of Illinois at Chicago, Estados Unidos; professora adjunta do Departamento de Arquitetura e Urbanismo da UFSC.

E-mail: marinatsiq@ gmail.com.

Artigo recebido em 24 de agosto de 2015 e aprovado para publicação em 9 de abril de 2016.

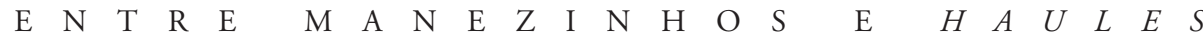

o que denominamos ao longo deste artigo de manezinhos, afirmam-se como sendo os verdadeiros moradores da cidade, com direitos efetivos no usufruto dela. Ao tentar preservar suas tradiçôes culturais e seu estilo de vida, eles também procuram manter os benefícios de sua nascença em um local considerado privilegiado. Descritos como conservadores, mas ao mesmo tempo participando da exploração das riquezas naturais de Florianópolis, os manezinhos muitas vezes excluem os haules e hostilizam os que, segundo eles, "abusam de sua casa". Enquanto uma parcela dos novos moradores defende a qualidade de vida local que primeiro os atraiu, muitos dos imigrantes recentes fecham-se em bairros novos, sem relacionar-se de forma mais direta com o resto da cidade e modificando a paisagem urbana e natural agudamente. Ademais, muitos dos novos empreendimentos na cidade, de grande porte e de grande importância econômica para a municipalidade, são realizados a partir de capitais externos à mesma, o que gera um excedente concentrado que, na maioria dos casos, não se fixa no local. O contato tenso entre esses segmentos populacionais pode ser lido nos jornais, ouvido nas conversas cotidianas, além de ser materializado nas pichaçóes dos muros da cidade. Não é possível distinguir claramente qual a cultura dominante ou quem é excluído. Em Florianópolis, o propulsor de identificação é o apego que esses velhos e novos moradores têm pela cidade.

O desafio é claro nesse caso: tentar promover as possibilidades democráticas através da cultura urbana. Em primeiro lugar, o reconhecimento da memória social, enfim, da pluralidade de identidades culturais, é um dos pressupostos para se pensar o cidadão florianopolitano. $\mathrm{O}$ acesso aos bens urbanos locais e à participação na seleção e no modo de se apropriar deles também é um direito. Em conexão direta com a democracia, essas ações refletem-se nas possibilidades de integração social. É a vigência efetiva do princípio de igualdade, mas com direito à diferença, abusando da criatividade de quem monta, cotidianamente, estratégias de sobrevivência e de busca de pertencimento a uma realidade. E é desse modo, a partir desses múltiplos pontos de identificação - posicionalidades -, que será possível nos ver e nos reconhecer inseridos na cultura como nossa história e, assim, descobrir o lugar a partir do qual falamos. Afinal, projetar uma cidade é projetar uma sociedade e uma prática a ser incorporada ao cotidiano. Florianópolis encontra-se em um momento crucial desse debate, no qual precisa tomar a decisão sobre qual sociedade/cidade ela abrigará. Entre as discussôes sobre o seu novo Plano Diretor, este é o principal desafio a ser enfrentado

\section{REFERÊNCIAS BIBLIOGRÁFICAS}

ANDERSON, P. As origens da pós-modernidade. Rio de Janeiro: Jorge Zahar, 1999.

ARANTES, O. Cultura da cidade: animação sem frase. Revista do Patrimônio Histórico e Artístico Nacional, Brasília, n. 24, p. 229-241, 1996.

Uma estratégia fatal: a cultura nas novas gestóes urbanas. In: ; VAINER, C.;

MARICATO, E. A cidade do pensamento único: desmanchando consensos. Petrópolis: Vozes, 2000. p. 11-74.

ARGAN, G. C. História da arte como história da cidade. São Paulo: Martins Fontes, 2005.

BOSI, E. Memória e sociedade: lembranças de velhos. São Paulo: Cia. das Letras, 2001.

BOURDIEU, P. Razóes práticas: sobre a teoria da ação. Campinas: Papirus, 1996.

CABRAL, O. Nossa Senhora do Destêrro. Florianópolis: Lunardelli, 1979. 
CANCLINI, N. G. Consumidores e cidadãos: conflitos multiculturais na globalização. Rio de Janeiro: Ed. UFRJ, 2006.

CARDOSO, F. H.; IANNI, O. Cor e mobilidade social em Florianópolis: aspectos das relaçóes entre negros e brancos numa comunidade do Brasil Meridional. São Paulo: Nacional, 1960.

CASCAES, F. O fantástico na Ilha de Santa Catarina. Florianópolis: Ed. da UFSC, 2000.

CASTELLS, M. A sociedade em rede. São Paulo: Paz e Terra, 2000.

CERTEAU, M. Teoria e método no estudo das práticas cotidianas. In: SZMRECSANYI, M. I. Q. F. (Org.). Cotidiano, cultura popular e planejamento urbano. São Paulo: FAU/USP, 1985. p. 3-17.

COMPANS, R. Empreendedorismo urbano: entre o discurso e a prática. São Paulo: Ed. UNESP, 2005.

FANTIN, M. Cidade dividida. Florianópolis: Cidade Futura, 2000.

HALL, S. A identidade cultural na pós-modernidade. Rio de Janeiro: DP\&A, 2006.

HARVEY, D. Condição pós-moderna. São Paulo: Loyola, 2005.

JAMESON, F. Espaço e imagem: teorias do pós-moderno e outros ensaios. Rio de Janeiro: Ed. UFRJ, 2004.

LEFEBVRE, H. O direito à cidade. São Paulo: Moraes, 1991.

LIMA, D. R. A abordagem ambiental no processo de desenvolvimento urbano de Florianópolis. 2002. Dissertação (Mestrado em Arquitetura e Urbanismo) - Faculdade de Arquitetura e Urbanismo, Universidade de São Paulo, São Paulo, 2002.

LOPEZ, R. A cidade intencional: o planejamento estratégico de cidades. Rio de Janeiro: Mauad, 1998.

MACAGNO, L. Cidadania e cidade (aventuras e desventuras do multiculturalismo). Espaço \& Debates, São Paulo, v. 23, n. 43-44, p. 51-59, 2003.

MACHADO, M. Maricultura como base produtiva geradora de emprego e renda: estudo de caso para o Distrito de Ribeirão da Ilha no município de Florianópolis - SC - Brasil. 2002. Tese (Doutorado em Engenharia de Produção) - Centro Tecnológico, Universidade Federal de Santa Catarina, Florianópolis, 2002.

PAIVA, E.; RIBEIRO, D.; GRAEFF, E. Florianópolis: Plano Diretor. Porto Alegre: Imprensa Oficial do Estado do Rio Grande do Sul, 1952.

PAOLI, M. C.; ALMEIDA, M. A. Memória, cidadania e cultura popular. Revista do Patrimônio Histórico e Artístico Nacional, Brasília, n. 24, 1996.

PEREIRA, E. A importação de conceitos modernistas no planejamento urbano de Florianópolis. In: SEMINÁRIO DE HISTÓRIA DA CIDADE E DO URBANISMO, 6., 2000, Natal. Anais do VI Seminário de História da Cidade e do Urbanismo. Natal: PPGAU/UFRN, 2000. p. 1-15.

PEREIRA, N. V.; PEREIRA, F. V.; SILVA NETO, W. J. Ribeirão da Ilha-vida e retratos: um distrito em destaque. Florianópolis: Fundação Franklin Cascaes, 1991.

PIMENTA, M. C. A. (Org.). Florianópolis do outro lado do espelho. Florianópolis: Ed. UFSC, 2005.

REIS, A. F. Permanências e transformaçôes no espaço costeiro: formas e processos de crescimento urbano-turístico na Ilha de Santa Catarina. 2002. Tese (Doutorado em Arquitetura e Urbanismo) - Faculdade de Arquitetura e Urbanismo, Universidade de São Paulo, São Paulo, 2002.

REZENDE, V. Planejamento urbano e ideologia. São Paulo: Civilização Brasileira, 1982.

RIZZO, P. M. B. Do urbanismo ao planejamento urbano: utopia e ideologia: caso de Florianópolis, 1950 a 1990. 1993. Dissertação (Mestrado em Geografia) - Centro de Filosofia e Ciências Humanas, Universidade Federal de Santa Catarina, Florianópolis, 1993. 
SÁNCHEZ, F. A reinvençâa das cidades para um mercado mundial. Chapecó: Argos, 2003.

SILVEIRA, L. R. M. A defesa de um espaço público por natureza: a Ponta do Coral como bem coletivo. In PIMENTA, M. C. A. (Org.). Florianópolis do outro lado do espelho. Florianópolis: Ed. UFSC, 2005. p. 85-102.

SASSEN, S. As cidades na economia mundial. São Paulo: Studio Nobel, 1998.

SIQUEIRA, M. T. Entre a prática e o discurso: a formação de espaços simbólicos na Florianópolis contemporânea. 2008. Dissertação (Mestrado em Arquitetura e Urbanismo) - Faculdade de Arquitetura e Urbanismo, Universidade de São Paulo, São Paulo, 2008.

SMITH, N. The new urban frontier: gentrification and the revanchist city. New York: Routledge, 1996.

New globalism, new urbanism: gentrification as global urban strategy. Antipode, Hoboken, v. 34, n. 3, p. 427-450, jul. 2002.

SUGAI, M. I. As intervençôes viárias e as transformaçōes do espaço urbano - a via de contorno norte-ilha. 1994. Dissertação (Mestrado em Arquitetura e Urbanismo) - Faculdade de Arquitetura e Urbanismo, Universidade de São Paulo, São Paulo, 1994.

VAINER, C. Pátria, empresa e mercadoria: notas sobre a estratégia discursiva do Planejamento Estratégico Urbano. In: ARANTES, O.; VAINER, C.; MARICATO, E. A cidade do pensamento único: desmanchando consensos. Petrópolis: Vozes, 2000. p. 75-103.

VEIGA, E. V. Florianópolis: memória urbana. Florianópolis: Ed. UFSC; Fundação Catarinense de Cultura, 1993.

ZUKIN, S. Aprendendo com Disney World. Espaço \& Debates, São Paulo, v. 23, n. 43-44, p. 11-27, 2003.

. The naked city: the death and life of authentic urban places. Oxford: Oxford University Press, 2009. 